\title{
La expulsión de los moriscos de Andalucía y sus límites. El caso de Sevilla (1610-1613)
}

\author{
Michel BoegLin \\ Université de Montpellier \\ michel.boeglin@univ-montp3.fr
}

Recibido : 10 de febrero de 2010

Aceptado : 13 de octubre de 2010

\begin{abstract}
Resumen
Apenas terminada la expulsión de los moriscos valencianos a finales de 1609, el marqués de San Germán, don Juan de Mendoza, emprendía el desplazamiento de los cristianos nuevos de Andalucía, Murcia y villa de Hornachos, publicándose el 17 de enero de 1610 el bando de expulsión en Sevilla. A pesar de la intransigencia manifestada a la hora de aplicarse los bandos, el destierro distó mucho de realizarse de forma eficaz, debido, en particular, a las innovaciones constantemente aportadas y al tiempo que tardó el Consejo Real en resolver las dudas que surgían a la hora de interpretar los edictos reales. Las órdenes posteriores de completar y acabar dicha operación, a través de las segunda y tercera expulsión, daban cuenta del carácter apresurado del primer operativo y revelaban las numerosas complicidades de la que habían podido valerse los moriscos a la hora de quedarse.
\end{abstract}

Palabras clave: Moriscos, Sevilla, Expulsión, s XVII, bando real, armada, solidaridades.

\section{The expulsion of the Spanish Moriscos from Andalusia and its limits. The case of Seville (1610-1613)}

\begin{abstract}
As soon as the Moriscos were expelled from Valencia at the end of 1609, Don Juan de Mendoza, marquis of San Germán, started the expulsion of the descendants of Moors from Andalusia, Murcia and Hornachos (Badajoz). In fact, on 17 January 1610, the edict of expulsion was published in Seville. However, in spite of the intransigence showed when these edicts were applied, the exile process was far from being carried out successfully. This was due to constant changes but also to the fact that it took time to the Royal Council to solve out the doubts about the interpretation of royal edicts. Subsequent edicts, in order to complete this operation, through a second and then a third expulsion, demostrated the rushed nature of the first operation and revealed that the Moriscos could rely on a great number of complicities when they decided to stay.
\end{abstract}

Key Words: Moriscos, Seville, Andalusia, $17^{\text {th }}$ Century, royal edicts, army, solidarities.

\section{Referencia normalizada}

Boeglin, M. (2011). "La expulsión de los moriscos de Andalucía y sus límites. El caso de Sevilla (16101613)". Cuadernos de Historia Moderna, Vol 36.: pp. 89-107 
Sumario: La primera expulsión de Sevilla. 1. Riquezas y exilio 2. El destino de los niños 3. Los "privilegiados" y eximidos del bando, Las segunda y tercera expulsiones de Andalucía, El proyecto de segunda expulsión, La inflexible aplicación del bando, El fin de la operación, Conclusión, Apéndice. Carta del marqués de La Algaba a Su Majestad. 5 de julio de 1611.

La expulsión de los moriscos de Andalucía suscitó poco interés en la historiografía, tanto entre los autores del siglo XVII como posteriores hasta una fecha reciente ${ }^{1}$. Poco o mal informados desde Pamplona y Valencia desde donde escribían en el siglo XVII, Marcos Guadalajara y Javiercomo Jaime Bleda coincidían para afirmarque la expulsión de los moriscos de Andalucía ofrecía poca materia para una crónica². En sus Anales de Sevilla, Diego Ortiz de Zúñiga podía escribir a finales del XVII, a propósito de los moriscos, que "en Sevilla había muy pocos y así fue fácil y poco ruidosa su expulsión 3", reflejo del común desinterés por la comunidad de cristianos nuevos. Ésta representaba, no obstante, a la hora de ser expulsada, cerca de 7500 personas en la sola ciudad de Sevilla y constituía así la mayor comunidad de Castilla ${ }^{4}$. Sin embargo, tanto por el número de deportados como por ser el primer desplazamiento masivo en realizarse enlaCoronadeCastilla,laexpulsiónsuscitónumerososinterrogantesyfuesobradamente más compleja y dificultosa que lo dejaron entender los autores del siglo XVII 5 .

Apenas terminado el destierro de los moriscos de Valencia a finales de 1609, en efecto, empezaba la organización del desplazamiento de los cristianos nuevos

${ }^{1}$ Este artículo es la traducción al castellano de una comunicación presentada en el Congreso de París L'expulsion des morisques, organizado por Bernard VinCENT, y patrocinado por l'Ecole des Hautes Etudes en Sciences Sociales, el Colegio de España y la Casa de Velázquez, los 2 y 3 de julio de 2009, que se publicará próximamente.

${ }^{2}$ Guadalajara y Javier, M. de, Prodición y destierro de los moriscos, Pamplona, 1614, $\mathrm{f}^{\circ} 28 \mathrm{v}$ que confiesa no haber podido consultar toda la documentación relativa a la expulsión para Andalucía; Bleda, J. Coronica de los moros de Valencia, 1618, Valencia, p. 1037-1041.

${ }^{3}$ Ortíz de ZúÑIgA, D., Anales eclesiásticos y seculares de la muy noble y muy leal ciudad de Sevilla ..., Sevilla, 1795, 5 vol, vol. 4, p. 225.

${ }^{4}$ Durante mucho tiempo, la comunidad morisca de Sevilla fue objeto de un relativo desinterés sin contar con ningún estudio monográfico de interés a pesar de su importancia. Uno de los primeros trabajos sobre demografía y sociología del conjunto del colectivo morisco en Sevilla fue el de PIKE, Ruth, en los años setenta: «An urban minority: the moriscos of Seville», International Journal of Middle East Studies, 2 (1971), p. 368-375. Por su parte, Rafael Pérez García y Manuel F. Fernández Chaves han analizado diversos aspectos de la integración de los moriscos en Sevilla: véase por ejemplo «La Iglesia y los moriscos en Sevilla. El retroceso de una frontera cultural (1569-1609)», Iglesias y fronteras, Jaén, 2005, p. 621-631. Su reciente libro En los márgenes de la Ciudad de Dios: moriscos en Sevilla, Valencia, 2009 aborda la cuestión de la minoría frente a las autoridades locales y los cabildos a partir de fuentes sevillanas. Sobre diversos aspectos de la sociedad morisca en Sevilla, ver BoEgLIN, Michel, Entre la Cruz y el Corán. Los moriscos de Sevilla, Sevilla (en prensa) en que van recopilados varios estudios que publiqué sobre dicho grupo a nivel sociológico, demográfico y religioso en los últimos diez años. Para una bibliografía más extensa de los moriscos en Sevilla remito al apartado bibliográfico de ambas obras.

${ }^{5}$ Serrano y Sanz, M. fue uno de los primeros historiadores en realizar una estimación de los expulsados de Andalucía, que estimaba en unos 21.617 moriscos : «Nuevos datos sobre la expulsión de los moriscos andaluces», Revista contemporánea, tomo XC (1893), p. 113-127, pp. 113-127. Henri Lapeyre, completando los datos de Serrano y Sanz, los estima en unas 30.000 personas: Lapeyre, H. Géographie de l'Espagne morisque, París, 1959, pp. 149-150, pp. 165-166. 
castellanos asentados en Andalucía. Se realizó según nuevas modalidades en muchos aspectos, procurándose paliar ciertos inconvenientes que había planteado la operación valenciana y adaptándola a los fueros castellanos. Supuso para los oficiales, en estrecho contacto con el Consejo Real, buscar soluciones constantes para agilizar y acelerar el operativo y adaptarlo a las órdenes emanadas de Madrid, a veces contradictorias ${ }^{6}$. El estudio de la correspondencia del marqués de San Germán y de los diversos oficiales encargados de llevar a cabo los bandos de expulsión revelan las diversas dificultades en la puesta en obra del dispositivo?.

En el momento de la expulsión, los oficiales encargados de aplicar el bando se enfrentaron con un complejo entramado entre cristianos viejos y moriscos en Sevilla y una diversidad de actitudes de los moriscos con respecto a la sociedad cristiana. Ante aquella diversidad del grupo, que ya no se puede presentar como unánimemente díscolo y reacio a la integración, la percepción de los moriscos por las autoridades encargadas de la expulsión fue progresivamente cambiando a medida que se ponían en obra las medidas decididas en el Consejo Real ${ }^{8}$. Las insuficiencias de la primera expulsión en 1610 fueron tales que la operación tuvo que ser repetida en dos ocasiones para rematarse; y las dificultades en realizar las segunda y tercera expulsiones daban cuenta tanto del empeño de muchos moriscos en quedarse en sus tierras como de las numerosas complicidades de las que pudieron valerse para eximirse del éxodo.

\section{La primera expulsión de Sevilla}

Apenas terminada la expulsión de los moriscos valencianos, se publicaba el 17 de enero de 1610 el bando de expulsión en Sevilla, con la mayor solemnidad. Se pregonó en presencia del marqués de San Germán, don Juan de Mendoza, encargado de aplicarlo en Andalucía, del Asistente de Sevilla y de las máximas autoridades judiciales, el alcalde más antiguo de la Audiencia, el alcalde de la justicia y los sargentos mayores, "y así se publicó con trompetas y cajas y con mucha quietud y sosiego y común aplauso de la ciudad".

\footnotetext{
${ }^{6}$ No entra en el marco de este estudio la cuestión de la toma de decisiones; pero queda evidente las luchas y facciones que se produjeron tanto a la hora de tomar la decisión de la expulsión como de definir sus modalidades en el Consejo: véase Benítez Sánchez Blanco, Rafael, Heroicas decisiones. La Monarquía católica y los moriscos valencianos, Valencia, 2001, p. 369-375; GARCía García, Bernardo J., La Pax Hispánica. Política exterior del Duque de Lerma, Lovaina, 1996; Benigno, Francesco, La sombra del rey: validos y lucha política en la España del siglo XVII, Madrid, 1994; Feros Carrasco, Antonio, El duque de Lerma: realeza y privanza en la España de Felipe III, Madrid, 2002.

${ }^{7}$ A. G. S., Estado (en adelante A. G. S., E ) 220 a 233 y 243-244.

${ }^{8}$ Sobre esta visión d el colectivo morisco como unánimemente díscolo y revoltoso, ver la obra del sevillano López Martínez, Celestino, Mudéjares y moriscos sevillanos Sevilla, 1935, una de las pocas monografías dedicadas a la cuestión morisca en Sevilla hasta una fecha reciente. Manuel F. Fernández y Rafael M. Pérez García en el último capítulo de su obra ya citada (pp. 363-449) abordan con detalle, la expulsión desde el punto de vista de las autoridades locales.

${ }^{9}$ A.G.S., E., 227, carta del marqués de San Germán a Su Majestad, del 17.1.1610; ibid. c. del 26.1.1610.
} 
La expulsión de Valencia, finalizada en diciembre de 1609, se había realizado rápidamente y sin contratiempo. Pero como lo señala Manuel Lomas Cortés, para llegar a tal fin, "el esfuerzo había sido exagerado para las escuadras que habían perdido gran cantidad de remeros y marineros", acelerando, además, el deterioro de la naves y dejando a muchas inservibles ${ }^{10}$. La expulsión valenciana significó, asimismo, un gasto considerable para la Hacienda Real y condujo a replantear la utilización de las escuadras en las siguientes deportaciones que se realizarían en Castilla. En adelante, y muy particularmente en el caso andaluz, los fletes privados se impusieron como modalidad principal, recayendo en los expulsados el coste de la travesía. Según el marqués de San Germán, bajeles pequeños, como saetías, carabelas, pinazas y "barcones destroncados", en cantidad en Sevilla, bastarían para el traslado a Africa del Norte de la población cristianonueva con la ayuda puntual de la flota militar ${ }^{11}$. Pero se tuvo que recurrir de forma creciente a naves extranjeras a medida que los moriscos pedían ser enviados a tierras de cristianos.

Con todo, la operación en Andalucía fue poniéndose en obra rápidamente; el primero de febrero de 1610, don Juan de Mendoza podía escribir, a propósito de la expulsión, haber "puesto la diligencia a mí posible y lo muestra la quietud con que se hace siendo a satisfacción de la ciudad y de los mismos moriscos ${ }^{12}$ ". En aquella fecha, ya estaban embarcadas en el puerto de Sevilla 2527 personas, a pesar de las malas condiciones y del tiempo riguroso que impedía a ciertas galeras atravesar el estrecho ${ }^{13}$.

Los embarques fueron sucediéndose a pesar de todo y, el 5 de febrero, poco antes de cumplirse el plazo de la expulsión, reducido a veinte días para los cristianos nuevos de Sevilla, expresaba el marqués su satisfacción por seguirse el plan previsto. En aquella fecha, ya casi estaban vaciados de sus moradores los barrios moriscos de la capital hispalense y, según el dispositivo ideado, seguían los de las ciudades vecinas:

en embarcándose los moriscos de Córdoba, Ecija Carmona y alguna parte del estado de Osuna no queda por esta parte cosa de consideración si no es algunos tan pobres que por no ser conocidos sea necesario buscarlos para embarcarlos y los que tuvieren dudas, que todo vendrá a ser poco número de gente y lo que fuere quedará tan dispuesto que cualquiera persona lo pueda ejecutar y el embarcarse esta gente pienso podrá ser en veinte días ${ }^{14}$

${ }^{10}$ Lomas Cortés, Manuel, «La organización naval hispánica y la expulsión de los moriscos (1609), Estudis: Revista de historia moderna, 31 (2005), p. 301-320, p. 319.

${ }^{11}$ A.G.S., E. 215, carta del 10.11.1609, el marqués de San Germán al Consejo. Ver Lomas CorTés, Manuel, «La contratación de mercantes extranjeros en la expulsión de los moriscos de Andalucía», Revista de historia moderna: Anales de la Universidad de Alicante, 27 (2009), pp. 193-218.

${ }^{12}$ A. G. S., E. 220, carta del 1.2.1610: carta del marqués de San Germán a Su Majestad.

${ }^{13}$ Ibiden.

${ }^{14}$ A. G. S., E. 220, el marqués de San Germán a Su Majestad, carta del 5.2.1610: "los moriscos de esta ciudad están ya embarcados casi todos y mucha parte de ellos van navegando con los pocos que han quedado no se puede tratar nada pero como ya son los últimos días del bando todos se han deshecho de sus haciendas, dineros y joyas y las tienen empleadas en mercadurías de las no prohibidas". 
Los cristianos nuevos de Úbeda y Baeza, aunque inicialmente previstos para ser embarcados en Sevilla, según el plan acordado por don Juan de Mendoza y el duque de Medina Sidonia fueron, por orden del Consejo, desviados para embarcar en Málaga, produciéndose roces con las autoridades locales y las tropas al mando del marqués de San Germán ${ }^{15}$. De la misma forma, los de Osuna, unas 250 personas, aunque incluidas en el bando, tuvieron que volverse del puerto malagueño al no poder cumplimentarse su embarque y escaparon así de la primera expulsión, con la autorización del marqués de San Germán ${ }^{16}$. El 9 de febrero, estaban saliendo en el río de Sevilla los moriscos de Hornachos, un grupo de unas 4500 personas, y los de Córdoba (3600) a los que habían de seguir los 1100 moriscos de Écija ${ }^{17}$.

Las tropas encargadas de realizar la expulsión, respaldadas por los corregimientos y señores de los distintos poblados y ciudades llevaron a cabo su misión con una eficacia puramente militar, aplicando con una fría y precisa mecánica las últimas decisiones cogidas en Madrid para acabar con la cuestión morisca en Castilla. En apariencia, el operativo se había realizado sin dificultades y fue la visión que presentaron las crónicas de la expulsión. No obstante, retrasos se habían acumulado debidos más a las "novedades" y cambios introducidos por el Consejo Real en la expulsión de los moriscos de Castilla con respecto a la de los valencianos, apenas acabada entonces.

\section{Riquezas y exilio}

En primer lugar, en un momento previo a la expulsión, la decisión de prohibir en adelante a los moriscos llevarse letras de cambio, cédulas, metales preciosos, joyas o dinero, sino el que fuere menester para los gastos del flete de los navío y del viaje, había supuesto una gran novedad con respecto a la expulsión de los de Valencia ocurrida poco antes. Oficialmente, se trataba de impedir que estas riquezas pudiesen servir a los Estados enemigos de la Corona a los que acudían los expulsados aunque también permitió aminorar el impacto económico de la expulsión. Significó un cambio que aumentó considerablemente los trámites. Sólo podían llevarse bienes muebles y ganado y el inventario de bienes raíces y el registro de los moriscos al embarcar retrasaron considerablemente las operaciones. El 17 de enero de 1610, confesaba el marqués de San Germán:

${ }^{15}$ A. G. S., E. 220, carta del marqués de San Germán a Su Majestad del 5.2.1610.

${ }^{16}$ A. G. S., E. 232, carta del marqués de San Germán a Su Majestad del 12.7.1611.

${ }^{17}$ A. G. S., E. 220, carta del marqués de San Germán a Su Majestad del 9.2.1610. Las cifras para Córdoba resultan ampliamente fluctuantes según los censos: Aranda Doncel los estima en 5500 personas, 7500 incluyendo los de los señoríos de Priego y de Carcabuey: Aranda Doncel, Juan, Los moriscos en tierras de Córdoba, Córdoba, 1984. p. 364; de los 4500 moriscos de Hornachos, sólo se tiene constancia del embarque en Sevilla de 2500 de éstos. Lapeyre, Henry, Géographie de l'Espagne morisque, p. 205. 
espero en Dios que se ha de hacer esta expulsión con mucha quietud aunque no tan brevemente como la de Valencia por ser más embarazosa y de más trabajo y ocupación porque a los moriscos de aquel reino como Vuestra Majestad sabe, se les permitió que llevasen la moneda de oro, plata y joyas que se pudiesen y a éstos se les prohíbe que lo hagan y demás de ello que no lleven letras de cambio y se les permite que lleven los bienes muebles y semovientes empleados en mercadurías no prohibidas compradas en los naturales de estos reinos o en frutos de la tierra y habiendo de hacer las visitas como Vuestra Majestad lo manda, es menester tiempo pero haráse lo posible por abreviar, valiéndome todas las embarcaciones que hay en el río ${ }^{18}$.

En previsión del elevado número de desplazados que pasarían por Sevilla los trámites iban a ser considerables para llevar a cabo la expulsión esta vez, tanto más cuanto que era la primera vez que se realizaban dichos inventarios y controles:

los requisitos de la embarcación son tantos que no puede dejar de ser muy larga y aunque algunas veces he representado a Vuestra Majestad que esta embarcación es muy diferente que la de Valencia, después que la he tocado con las manos veo más clara la dificultad porque Vuestra Majestad manda que todas las costas que aquí se causaren sean a la de los moriscos y así es menester hacer la cuenta con cada uno de ellos de por sí... y habiéndose de hacer esto con más de cuarenta mil personas que se han de embarcar por el río de esta ciudad, no puede dejar de causar dilación ${ }^{19}$.

A pesar de tenerse dictadas drásticas medidas para escarmentar a los "contrabandistas" que procurasen sacar riquezas, se tenían informaciones de fraudes continuos a las normativas. En Castilla, Luis Cabrera de Córdoba, en sus Relaciones del 13 de marzo de 1610, narraba que habían quitado más de "50 000 escudos en oro y joyas que llevaban escondidos y [con] cadenas dentro de sogas de esparto" los moriscos de Castilla la Vieja y la Nueva y Extremadura a la hora de pasar por Burgos para dirigirse hacia Francia ${ }^{20}$ ". Cuando en Sevilla la expulsión de los moriscos andaluces tocaba a su fin, algunos de los cordobeses, entre los últimos en salir, procuraron invertir su hacienda en perlas, diamantes y otras piedras preciosas. Emplearla en dichos bienes no iba en contra del bando con tal de que se abonaran los almojarifazgos y así procuraron acogerse a la medida aunque el marqués de San Germán optó por no confirmar aquel derecho hasta que llegasen a Sevilla a embarcar, obligándoles por tanto a emplear su fortuna en otros bienes muebles ${ }^{21}$.

Los moriscos también pudieron contar con la colaboración de determinados grupos para evadir fondos hacia el extranjero. A finales de marzo de 1610, durante

\footnotetext{
${ }^{18}$ A. G. S., E. 227, carta del marqués de San Germán a Su Majestad, 17.1.1610.

${ }^{19}$ A. G. S., E. 220 1. 2. 1610 carta del marqués de San Germán.

${ }^{20}$ Cabrera de Córdoba, L., Relaciones de las cosas sucedidas en la Corte de España desde 1599 hasta 1614, Madrid, 1857, pág. 398-399

${ }^{21}$ A. G. S., E. 220 carta del marqués de San Germán a Su Majestad, 5.2.1610.
} 
la expulsión de los moriscos de las dos Castillas, la frontera con Francia fue cerrada y los moriscos orientados hacia el puerto de Cartagena, tras temerse la excesiva concentración de ellos en la frontera y su posible utilización por el rey vecino; en el mismo tiempo se "había hallado portugueses que contrataban allá y les pasaban todo el oro y plata que querían, con lo cual registraban muy pocos en Burgos ${ }^{22}$. . Aquello se produjo no sólo en la frontera sino en distintas ciudades castellanas y probablemente andaluzas, donde los moriscos pudieron valerse de la preciosa colaboración de judíos conversos quienes, gracias a sus extensas redes familiares en Francia y en Túnez, facilitaron la salida de parte de su fortuna. El trámite tenía un precio elevado, que oscilaba entre el 20 y el $30 \%$ del dinero evadido y probablemente sólo una escasa minoría pudo aprovecharse de estas artimañas ${ }^{23}$.

Ya el primero de febrero, reconocía el marqués de San Germán que le habían "venido a dar cuenta de que por caminos muy escondidos se embarca dinero y joyas sin bastar las diligencias que humanamente puedo yo hacer y, así, he hecho pregonar hoy aplicando por tercias partes cualquiera hacienda que por denunciación se cogiere ${ }^{24}$. Ante las dificultades a reunir pruebas de las constantes infracciones a las normativas, pareció preferible recompensar la delación de aquellos métodos.

\section{El destino de los niños}

En segundo lugar, los retrasos habían ido acumulándose a partir del momento en que se decidió arrebatar los niños de menos de siete años a los moriscos que se dirigieran hacia tierras musulmanas ${ }^{25}$. El bando publicado el 17 de enero señalaba que todos los moriscosdecualquieredadfueran expulsados, exceptuandoúnicamentealos esclavos ${ }^{26}$, quienes permanecerían en la Corona por ser propiedad de sus amos. No obstante, los críos fueron retirados a sus padres cuando se destinaba a costas islámicas, aunque la medida parece haber tardado en ponerse en obra. Sólo fue el 16 de febrero de 1610, un mes después de pregonarse el bando, cuando don Juan de Mendoza anunciaba haber empezado a cumplir con la orden de retirar los niños a los moriscos embarcados en navíos con rumbo a Berbería y advertía de ello al duque de Medina Sidonia para que hiciese lo mismo en sus posesiones ${ }^{27}$. Hacía más de dos semanas que los moriscos de Sevilla y de los poblados colindantes habían empezado a embarcar.

\footnotetext{
${ }^{22}$ Cabrera de Córdoba, L., Relaciones..., p. 402; H. Lapeyre, Géographie..., pp. 160-161.

${ }^{23}$ Bernabé Pons, Luis F., «Notas sobre la cohesión de la comunidad morisca más allá de su expulsión de España», Al-Qantara: Revista de estudios árabes, 29-2 (2008), p. 307-332, pp. 311-313.

${ }^{24}$ A. G. S., E. 220 carta del 1.2.1610.

${ }^{25}$ Betrán Moya, José L., «Los niños moriscos antes y después de la expulsión», Historia y perspectivas de investigación : estudios en memoria del profesor Angel Rodríguez Sánchez, 2002, p. 295300. Sobre la expulsión en Valencia y Denia más particularmente, véase LoMAs CorTés, M., El puerto de Dénia y el destierro morisco (1609-1610), Valencia, 2009, pp. 221-229.

${ }^{26}$ Bando publicado por BledA, J., Corónica ..., págs. 1038-1040, 1039 col. 1

${ }^{27}$ A. G. S., E. 220, carta del marqués de San Germán a Su Majestad del 16.2.1610.
} 
La casualidad quiso que la medida empezara a ponerse en obra con los moriscos de las tierras de Hornachos, con aquellos moriscos vistos, precisamente, como los más reacios a la integración a la fe cristiana, acusados de los peores crímenes y fechorías ${ }^{28}$. En toda lógica, esta nueva condición iba a obligar a numerosas familias a cambiar el destino de su viaje: "la causa porque digo que se ha de alargar la embarcación es porque de miedo de verse quitar los hijos no ha de haber ninguno que deje de ir a tierra de cristianos, a que yo les ayudaré como Vuestra Majestad manda. Pero no dejará de conocerse bien la dificultad que habrá de embarcaciones pues las galeras de Vuestra Majestad no las podrán ayudar porque no es posible enviarlas a Francia con gente, ni pueden hacer otro pasaje que a Berbería ${ }^{29 "}$. Difícilmente podrían las galeras acudir a puertos que no fueran españoles. Mas aún, el plan inicial de orientar a parte de los moriscos hacia Málaga hacía temer no hallar suficientes barcos en este puerto para llevar a los expulsados a Francia o a Italia ${ }^{30}$.

Aquel CAMBIO requería encontrar barcos de tonelaje suficiente y en número importante para trasladar a los expulsados. Suponía alargar tanto la duración del viaje como los costes, en una población en que la gran mayoría eran pobres. Se había decidido en el Consejo Real que los más ricos se encargarían de sufragar los costes de los más pobres con su hacienda, pero en las comunidades de cristianos nuevos más necesitadas se llegó a extremos como en Écija donde los moriscos pedían que les vendieran para que sus familias pudiesen irse a tierras de cristianos sin separarse de su progenitura. Escribía don Juan de Mendoza al Rey:

Vuestra Majestad tiene mandado que los ricos lleven a los pobres y esto se ha guardado hasta ahora pero hay algunos tan consumidos que de ninguna manera tienen con qué remediarse y las costas y fletes que se les hacen son tan grandes sin ser posible excusarlo que prometo a Vuestra Majestad que muchas veces me veo muy apretado y ahora lo estoy con los de Écija porque me dicen que los venda y envíe a tierras de cristianos y realmente ni ellos tienen cómo ir, ni yo con qué socorrerlos, ni orden de Vuestra Majestad para hacerlo ${ }^{31}$.

El número de niños retirados a sus padres en Sevilla se desconoce, pero probablemente no fuera tan elevado como en Valencia, donde una carta con fecha del 4 de abril de 1610 señalaba que habían sido recogidos en familias o por la Iglesia 1832 niños de menos de siete años, abandonados, perdidos o robados por católicos que, con un celo excesivo, deseaban sustraerlos al Islam y sin contar aquellos robados por la soldatesca ${ }^{32}$. En total, la cifra avanzada por H. Lapeyre de 2500 niños de menos de doce años perdidos o raptados y recogidos en las diversas diócesis del Reino de Valencia es probablemente fiable, a pesar de que el bando no prohibiera expresadamente a los padres llevarse a sus niños a tierras islámicas ${ }^{33}$.

\footnotetext{
${ }^{28}$ Ibiden.

${ }^{29}$ Ibiden.

${ }^{30}$ Ibiden .

${ }^{31}$ A. G. S., E. 220 D. Juan de Mendoza, 16.2.1610

${ }^{32}$ A. G. S., E. 228, carta del marqués de San Germán a Su Majestad del 17.4.1610. Ver también LAPEYRe, H., Géographie..., p. 64.

${ }^{33}$ Boronat y Barachena, P., Los moriscos españoles y su expulsión, Valencia, 1901, 2 vol., vol. 1, pág. 522-536; LAPEYre, H., Geographie de l'Espagne..., pp. 63-64
} 
En Sevilla, el número de aquellos niños fue en toda lógica menos elevado. Al llegar la orden del Consejo de retirarlos sólo a mediados de febrero, cuando ya habían salido la mayoría de los moriscos de Sevilla y sus inmediaciones, su número hubo de ser sensiblemente más bajo que en Valencia. Los primeros en ser separados ni fueron listados según reconocía el marqués de San Germán ${ }^{34}$. El mismo día en que se ordenaba quitar a los niños menores de siete años de los barcos con destino a países musulmanes, don Juan de Mendoza acudía a la catedral y se entrevistaba con el chantre para transmitirle el deseo del Rey de que se recogieran aquellos niños y, al día siguiente, "de parte de todo el cabildo me vino a ver y ofrecer que recibirían 340 muchachos niños y niñas y que del remedio de las muchachas después de criadas se encargaba la Iglesia. Yo se le agradecí mucho y ofrecí representarlo a Vuestra Majestad. No sé que cantidad de niños se recibirán aquí pero no serán tan pocos que mientras no hay quien los reciba no [sic] será menester gasto considerable ${ }^{35}$ ". En agosto de 1610, durante el éxodo de los moriscos de las dos Castillas, ante el elevado numero de niños en pecho y en baja edad de los que nadie quería hacerse cargo, don Juan de Mendoza obtuvo del Consejo que, cada año, se destinara a la crianza de los niños cierta suma sacada de los bienes raíces dejados por los moriscos ${ }^{36}$.

\section{Los "privilegiados" y eximidos del bando}

Por fin, la cuestión más delicada era la de aquellos que pudiesen eximirse del bando acogiéndose a las excepciones previstas por éste. Ya el 9 de enero de 1610, el Asistente había pedido encarecidamente que el Consejo tratara con misericordia los casos de matrimonios mixtos, en número muy elevado en la ciudad ${ }^{37}$. El marqués de San Germán reiteró en diversas ocasiones dicha petición, de forma insistente al acercarse el plazo de ejecución del bando, ante la urgencia del caso y el número de matrimonios entre cristianos nuevos y moriscos: "suplico a Vuestra Majestad mande que se me responda luego a esto porque en esta ciudad hay tanta mezcla que algunas de estas cosas tocan a gente que estaba en diferente reputación y en el entretanto Vuestra Majestad no me mandare avisar iré ejecutando el bando sin reservas a nadie ${ }^{38 ",}$, escribía el 17 de enero. Cuando ya habían salido gran parte de los moriscos de Sevilla y sus alrededores, una provisión real, la "declaración de las dudas" vino a zanjar la cuestión ${ }^{39}$. En conformidad con el sistema patrilineal de transmisión de la honra, sólo podrían quedarse las moriscas

${ }^{34}$ A. G. S., E. 220 carta del 16.2.1610. D. Juan de Mendoza: "he hecho visitar todos los navíos de los moriscos que habían embarcados en este río y se les han quitado los niños como Vuestra Majestad manda a los que estaban fletados para Berbería. Se entregaron a personas, pero relación de los niños y de éstas, no se pudo sacar ni enviar...".

${ }^{35}$ A. G. S., E. 220 carta de D. Juan de Mendoza del 16.2.1610.

${ }^{36}$ A. G. S., E 228 carta s. f., recibida en el Consejo Real el 22.8.1610.

${ }^{37}$ A.G.S., E. 227, 9.1.1610.

${ }^{38}$ A. G. S., E. 227, carta del 17.1 .1610 ya citada. La misma amenaza aparece en el correo del 20.1.1610.

${ }^{39}$ Instrucción publicada por BLEDA, Jaime, Coronica ..., pp. 1040-1041. 
casadas con cristianos viejos; en cambio, el esposomoriscoy sus descendientes deberían abandonar los reinos de la Corona, dejándose la posibilidad a la mujer únicamente entre pedir la separación o seguir a su marido en el extranjero, incluso a tierras islámicas, si tal era su deseo. En semejante caso, los niños menores de siete años serían retirados de la misma forma que para los otros moriscos ${ }^{40}$. El bando, en cambio, no se aplicaba para los turcos y berberiscos y por tanto no afectaba a los miembros de estas minorías, salvo en caso de matrimonio mixto.

Por su parte, varios obispos intervinieron para atenuar el rigor del bando; el arzobispo de Granada, don Pedro Vaca de Castro y Quiñones, poco antes de ser promovido a la silla de Sevilla, vacante desde la muerte de don Fernando Niño de Guevara, a principios de 1609, protestó vehementemente por las opciones escogidas para la expulsión ${ }^{41}$. La "declaración de las dudas" preveía en su quinto punto que los descendientes de los que se hubiesen convertido antes de la reducción general y que habían vivido cristiana y ejemplarmente podían quedarse si tenían la aprobación de los obispos.

La cláusula provocó airadas discusiones entre el marqués encargado de la expulsión y los prelados andaluces y murciano, por considerar don Juan de Austria que se daba una interpretación demasiada laxa del texto. Los obispos de Cartagena y Córdoba se negaban a considerar a los mudéjares de las primeras conversiones como incluidos en los bandos por considerarlos a todos como cristianos viejos, puesto que lo eran de derecho. Aquella postura suscitó las vehementes protestas del marqués de San Germán :

el Obispo de Córdoba [...] ha alargado la intención de Vuestra Majestad de más de lo que fuera justo, que los corregidores de Granada, Úbeda y Baeza van reservando gente de la que tampoco debe quedar porque conforme Vuestra Majestad manda en la declaración de las dudas, sólo se han de quedar aquellos que fueren descendientes de los que se convirtieron de su voluntad antes de la reducción general y de éstos no todos, sino los que hubieren vivido cristiana y ejemplarmente y tratádose como cristianos viejos, lo cual han de probar los prelados ${ }^{42}$.

La misma actitud seguían los corregidores de Granada, Úbeda y Baeza, negándose a contabilizar a los moriscos antiguos entre aquellos entendidos por el bando y apuntaba el Marqués que "haciendo esto los corregidores se va abriendo puerta para que se queden los más ricos y poderosos y haya inteligencias como me dicen las hay y aunque no se acabe de extirpar de una vez esta gente, que es el fin que Vuestra Majestad lleva ${ }^{43}$ ". Aquellos moriscos convertidos antes de 1502 formaban

${ }^{40}$ Resolución de su Majestad del 6 de febrero de 1610 publicado en Ignacio BaUER y LANDAUER, Papeles de mi archivo Relaciones y manuscritos (moriscos), Madrid, 1923, págs 169-170. El texto íntegro, con todos sus apartados fue editada por BlEDA, Jaime, Coronica..., pp. 1040-1041.

${ }^{41}$ Domínguez Ortiz, A. - Vincent, B., Historia de los moriscos, Madrid, 1978, apéndice VIII, pp. 281-282.

${ }^{42}$ A.G.S., E. 228 carta del 4.3.1610.

${ }^{43}$ Ibiden. 
sin lugar a dudas un colectivo mejor integrado a la sociedad cristiana y gozarían de una comodidad económica mayor a la de los deportados de Granada, llegados en condiciones difíciles a Sevilla en 1570. No obstante, el temor de los oficiales a que pudiesen valerse de sus relaciones y redes para escapar del bando constituía una preocupación constante.

A pesar de estas incógnitas que fueron resolviéndose progresivamente, la expulsión se llevó a cabo con todo rigor y con la celeridad que deseaban las autoridades reales, sin provocar mayores disturbios en Andalucía occidental. A principios de abril de 1610, Luis Cabrera de Córdoba podía escribir en sus relaciones, "los de Andalucía han salido todos, y de Granada quedaban muy pocos por falta de navíos, que los esperaban a la costa de la mar con mucha descomodidad, y sólo han quedado los exceptuados por el bando ${ }^{44}$ ". Más de 18000 moriscos habían salido desde Sevilla o transitado por ella entre enero y febrero de 1610 y en total, unas 31000 personas habían abandonado Andalucía antes de finalizar el año $0^{45}$.

En el distrito de Sevilla, los privilegiados y casos reservados en nombre del marqués de San Germán, que habían sido excluidos del primer bando de expulsión alcanzaban según su sucesor, más de 1000 personas, a las que habría que añadir a los miembros de su familia supuestamente ${ }^{46}$. Muchos otros, contando con la complicidad de sus vecinos que, por interés o por misericordia, los amparaban y escondían, pudieron sustraerse al bando. Lo que preocupaba, no obstante, era la vuelta cada vez más importante de moriscos desde las costas africanas.

\section{Las segunda y tercera expulsiones de Andalucía}

En diciembre de 1610, ni siquiera cumplido un año desde la lectura del bando, se registraban las primeras vueltas. Más de 8.000 moriscos habían sido enviados desde Sevilla hacia Ceuta y Tánger para adentrarse desde allí en el territorio marroquí; al pie de las murallas de las ciudades fueron concentrándose en número cada vez creciente los que, sin permiso para entrar en los recintos, no se atrevían a penetrar en el reino marroquí por miedo a malos tratamientos, exacciones diversas y robos de los que eran víctimas. Rápidamente se hallaron en una situación desesperada. Las vueltas hacia España fueron multiplicándose en conformidad con lo que temía el duque de Medina Sidonia quien, en diciembre de 1610, escribía que "se ha entendido que cada día volverá mucha de esta gente por el mal tratamiento que se les hace en Berbería, si no se pone el remedio en el castigo... conviene mucho que haya declaración y escarmientos en estos excesos... ${ }^{47 "}$. Paralelamente, fueron costeándose navíos para que pudiesen abandonar las posesiones africanas de la Corona y dirigirse hacia Francia o Italia; por su parte el duque de Medina Sidonia, hizo venir de las costas africanas a 59 niños

\footnotetext{
${ }^{44}$ Cabrera de Cordoba, L., Relaciones..., p. 402.

${ }^{45}$ Según los cálculos de Lapeyre, H., Géographie..., pp. 155-156.

${ }^{46}$ A. G. S., E. 232 carta del 12.7.1611.

${ }^{47}$ A. G. S., E. 228 carta del 21.12.1610.
} 
menores de tres años arrebatados a sus padres en $1612^{48}$. Algunos, dirigiéndose desde las costas maghrebíes hacia Francia o Italia, convinieron con los maestros de la naves ser dejados en las costas españolas; otros fueron abandonados en ellas por capitanes poco escrupulosos como pasó a finales de 1610, cuando cerca de 300 moriscos fueron así echados en la costa de Cartagena de una nave inglesa en que viajaban, en vez de ser llevados a Francia ${ }^{49}$.

\section{El proyecto de segunda expulsión}

A pesar de las penas de galeras y azote que se impusieron a los que volviesen, fueron multiplicándose los casos de naves trayendo o desembarcando clandestinamente a moriscos en sus antiguas tierras, sin que las autoridades pudiesen atajarlo, haciendo rápidamente contemplar la necesidad de una nueva expulsión. Aquellos musulmanes de España que habían sido bautizados eran vistos desde África del Norte, en muchos casos, como apostatas de la fe del Profeta; a ello se añadía la reacción de las poblaciones locales frente a la llegada masiva de los españoles en las costas. Progresivamente el número de aquellos que volvían fue aumentando; y a éstos, se añadían los numerosos moriscos que seguían en Andalucía en 1611, entre los que habían logrado sustraerse a la orden de expulsión y los que tenían pleitos pendientes.

A mediados del febrero de 1611, en previsión de una segunda expulsión y para despejar cualquier duda e interpretación, la junta de Madrid sobre moriscos decidió acabar con la distinción entre granadinos y moriscos antiguos. Éstos fueron incluidos en el segundo bando de expulsión, aunque podrían acogerse a un trato más suave por parte de las autoridades a la hora de salir. Según el conde de Salazar, aquellos moriscos bautizados antes de las conversiones masivas de 1502 merecían más favores y comodidad en la forma de ser expulsados y se les dejaría vender sus bienes raíces. Poco después, la cédula despachada en 22 de marzo de 1611 preveía que se expulsarían a los granadinos, incluso los que habían realizado informaciones que establecían que eran buenos cristianos, porque resultaban sospechosas. La sesión del Consejo de Estado del 12 de mayo de 1611 formalizó los deseos de Felipe III de expulsar a todos los moriscos que no se hubiesen integrado a la perfección a la sociedad cristiana abandonando sus rasgos culturales y sociales propios $^{50}$.

En Andalucía, más particularmente, los controles resultaban sobradamente más severos en vistas a la segunda expulsión. Tres comisarios fueron nombrados, D. Tadeo de Benavides para Córdoba, D. Francisco de Yrarrazabal en Granada y el caballero de la Orden de Santiago, don Alejo de Marimón con jurisdicción en Sevilla y su arzobispado. El 31 de mayo de 1611, el comisario nombrado para la ciudad hispalense y su partido recibía los poderes del Rey para que se expulsara de los reinos a los que habían vuelto y a los que se hubieran quedado en las diversas partes de

\footnotetext{
${ }^{48}$ A. G. S., E. 244 el duque de Medina Sidonia a S. M. el 21. 5. 1612.

${ }^{49}$ A. G. S., E. 22821.12 .1610

${ }^{50}$ Lapeyre, H., Géographie..., p. 177.
} 
Andalucía, "inhibiendo del conocimiento de estas causas a las chancillerías del reino de Granada y a la Audiencia de Sevilla" ${ }^{51}$.

La instrucción relativa a la segunda expulsión dejaba, no obstante, una cláusula que permitía a cualquier morisco acogerse a la protección del Rey y de su Consejo en caso de considerarse cristiano viejo. Resultó ser la única solución al amparo de la cual pudieron acogerse los moriscos:

si de los que no fueren notoriamente moriscos, ni tenidos por tales por algún aviso secreto, que se diese se entrase en sospecha, o indicios de que algunos hombres están en reputación de cristianos viejos o que no se ha sabido lo contrario, son o pueden ser moriscos, no se han de escudriñar ni averiguar estos indicios sin nueva orden nuestra sino avisarme de la tal sospecha y en qué se funda: y esperar a lo que yo mandare se haga $^{52}$.

En conformidad con las prerrogativas que le fueron concedidas, Marimón se mostró un adversario conspicuo de las cédulas anteriormente entregadas a moriscos para eximirlos de la primera expulsión, siendo sospechosas la mayoría, a sus ojos, de ser falsas y "siniestras". Para el caballero de la Orden de Santiago, tres grupos se habían eximido de la orden de expulsión y en adelante sus casos se revisarían. Se trataba por una parte de los viejos y tullidos que difícilmente podían efectuar el viaje del éxodo. Su caso planteaba pocas cuestiones pues el marqués de San Germán había ordenado que embarcasen todos los hombres y mujeres en estado válido, hasta 80 años. Pero dos otros colectivos de moriscos "privilegiados", según el término empleado por don Alejo de Marimón, iban a retener toda su atención: aquellos que eran, de derecho, cristianos viejos y, por otro lado, los que gozaban de particulares exenciones de nobleza recibidas en tiempos de los Reyes Católicos. Entre las dos últimas clases se ocultaban muchas falsas informaciones, según él,

que, mediante su inteligencia, cada uno ha sabido conseguir, y juzgando por las que a presente se están haciendo sospecho mal de las hechas. Estos tales son muchos, a pesar de la prudencia y rectitud del marqués de San Germán y conde de Salazar, todavía me ha parecido dar cuenta a Vuestra Majestad de ello para cumplir con mi obligación y satisfacer al vulgo con lo que Vuestra Majestad me será servido mandarme o sobre el particular de los que muestran haber probado ser cristianos viejos... ${ }^{53}$.

Para él, la primera expulsión distaba mucho de haber sida completa; el partido del duque de Medina Sidonia le parecía "estar bien limpio de moriscos, jasí lo estuviese

${ }^{51}$ Bleda, J., Coronica ..., p. 1043. Otro despacho fechado del mismo día ordenaba «que salgan todos los tales moriscos así granadinos como lo que llaman antiguos sin reservación ni dar lugar a las invenciones que usan los que tratan de quedarse o con informaciones siniestras», Ibiden, 1044.

${ }^{52}$ BledA, J., Coronica ..., p. 1044, del 31.5.1611. El bando de expulsión se prorrogó hasta junio de 1611

${ }^{53}$ A. G. S., E. 232 carta de D. A. de Marimón del 5.7.1611. 
Sevilla54!", lamentaba. En la capital se concentraba un número aún excesivo de moriscos, entre los que habían recibido exenciones del marqués de San Germán, los que se habían escondido para escapar de la expulsión y los que ya habían vuelto.

La junta de Madrid, dirigida por el Conde de Salazar, tenía todos los poderes para pronunciarse sobre los recursos presentados por los moriscos y sus fallos fueron rápidamente interfiriendo con la actividad de los oficiales de Alejo de Marimón. El caballero de la Orden de Santiago se vio enseguida envuelto en discrepancias con las autoridades locales y, al mismo tiempo, con la junta de Madrid, sin gozar del apoyo incondicional de la Corona, según trasluce por el tono irritado de sus correos. Su misión duró más de lo previsto por el empacho provocado por los numerosos recursos presentados por moriscos ante la junta de Madrid, las disyuntivas entre ésta y las interpretaciones inflexibles dadas por Marimón. También se produjeron roces entre sus hombres y los corregimientos pocos veloces a la hora de transmitir informaciones y entregar a los contrabandistas. El 15 de agosto, don Alejo Marimón confesaba su desidia ante la acumulación de recursos y su deseo de acabar cuanto antes con aquella misión y puntualizaba: "los moriscos que no tienen réplica estarán puestos surcando las aguas saladas, que no lo deseo poco y verme libre de esta Babilonia ${ }^{55 "}$.

Definía su modo de actuación: "no guardar sentencia favorable a ningún morisco que pareciera haber sido expulsado o pagado farda ${ }^{56 "}$, contribución a la que estaban sometidos los moriscos de Granada, y revisar las informaciones de buen cristiano que daban los moriscos, por ser falsas y siniestras, obtenidas fácilmente por el testimonio de cualquier vecino. En un correo del 23 de agosto de 1611, expresaba todo su rencor contra las receptorías que el conde de Salazar mandaba despachar "inhibiéndome cada día del conocimiento de las causas de estos moriscos que en procesión van a buscar el maná de esa junta que con tanta abundancia cae sobre ellos $^{57}$, arremetiendo contra el escribano de la junta ante el conde de Salazar y el Rey. Protestó contra la junta de Madrid, cuyas actuaciones siguió criticando en diversas ocasiones: en agosto, afirmaba no sentirse vinculado por las decisiones de la junta, pues "da cada día tantas receptorías y tan injustas que no es razón pasar por ellas", dos semanas después de que pidiera que los pleitos y personas les fueran remitidos, a causa del excesivo número de fraudes ${ }^{58}$. También fue quejándose de don Francisco de Irrarazábal, comisario para el antiguo reino de Granada, que no contestaba a sus correos, probablemente irritado por sus actuaciones excesivas y estilo tosco; a nivel local, se quejaba de no recibir los padrones de moriscos que le habían de transmitir los curas ${ }^{59}$.

\footnotetext{
${ }^{54}$ A. G. S., E. 232 carta de D. A. de Marimón del 15.8.1611.

${ }^{55}$ A. G. S., E. 232 D. A. de Marimón correo del 15.8.1611.

${ }^{56}$ A. G. S., E. 232 D. A. de Marimón correo del 15.8.1611.

${ }^{57}$ A. G. S., E. 232 D. A. de Marimón correo del 23.8.1611.

${ }^{58}$ A. G. S., E. 232 cartas del 23.8.1611 y 13.8.1611.

${ }^{59}$ A. G. S., E. 232 , carta de D. A. de Marimón del 23.8.1611.
} 


\section{La inflexible aplicación del bando}

La aplicación inflexible del bando real del 31 de mayo había provocado un movimiento de temor entre los moriscos. Muchos de los expulsados el año anterior se habían vuelto y acudieron a la junta de Madrid, intentando eludir los recursos entablados contra ellos en Sevilla, ante la intransigencia manifestada allí por Marimón y sus oficiales. Ante el rotundorechazo manifestado por el caballero de Santiago a la hora de contemplar excepciones, muchos preferían esconderse y acudir a la junta presidida por el conde de Salazar que era notoriamente menos rigurosa. Desde Madrid, difícilmente podían averiguarse en qué medida estaban fundadas las informaciones y mediante sobornos y apoyos, podían esperar ver sus causas prosperar ${ }^{60}$.

Al mismo tiempo, en diversas partes de Andalucía, Murcia y Castilla se dieron casos, entre los moriscos, de exaltación y ostentación de su identidad católica para procurar escapar del segunda bando de exclusión: como lo narraba Jaime Bleda, con su habitual sorna, "publicado el bando, creyeron los moriscos que con hacer demostraciones de cristiandad se dilataría la ejecución y podrían alcanzar se disimulase con ellos (sic) como otras veces. Hicieron procesiones con disciplinas y las doncellas descalzas, sus cabellos tendidos, poniendo sobre sus cabezas ceniza a imitación de los ninivitas, no querían tratar de disponer de sus bienes ${ }^{61}$ ". Muchos huyeron esperando ponerse a salvo del bando, yendo a poblaciones en las que no eran conocidos para hacerse pasar por cristianos viejos ${ }^{62}$ ". Muchas moriscas se casaron con cristianos por temor de salir de Castilla y, como lo explicaba J. Bleda, "metiéronse algunos frailes legos y, siendo casados, sus mujeres religiosas, también legas" en monasterios ${ }^{63}$. Estos casos fueron lo suficientemente frecuentes, al parecer, para que D. Alejo de Marimón pidiese desde Sevilla "que se le avise como procederá con los moriscos que se recogen y hay en los conventos de frailes y monjas ${ }^{64}$ " y que el Consejo le ordenara respetar las inmunidades eclesiásticas, aunque le instara a entrevistarse con los superiores de las órdenes para convencerlos de la necesidad de aplicarse el bando en sus casas ${ }^{65}$.

Casos específicos no zanjados por el marqués de San Germán iban a ser por otra parte vigorosamente tratados por el comisario. El grupo de 250 vecinos de Osuna quienes, un año antes, habían escapado a la expulsión general con la autorización del marqués de San Germán, fueron esta vez echados por los hombres de Marimón. Los moriscos antiguos o "convertidos" antes de la conversión general de 1502 conocieron el mismo destino: en Archidona, al norte de Sevilla, existía desde tiempos de Enrique IV una morería cuya importancia había considerablemente aumentado bajo

${ }^{60}$ Contra aquello protestaba Marimón: A. G. S., E. 232 Consulta hecha por el capitán Miguel Camarena al Sr Don Alejo de Marimón, del 13.8.1611. En repetidas ocasiones se quejaban que los moriscos recibían sentencias declaratorias de la junta, a pesar de constar sus nombres en los libros de la farda.

${ }^{61}$ Bleda, J. Coronica ..., p. 1059.

${ }^{62}$ Ibiden.

${ }^{63}$ Ibiden.

${ }^{64}$ A. G. S., E. 232 carta de D. Alejo de Marimón del 2.8.1611

${ }^{65}$ Ibiden. 
los Reyes Católicos con la llegada de moros de Granada. Los moriscos de aquel concejo volvieron a acogerse a una ejecutoría que les protegía de la expulsión $\mathrm{y}$, aunque habían sido exentos de pagar la farda, fueron expulsados ${ }^{66}$.

En la Algaba, se había añadido a partir de 1570 moriscos deportados de Granada a una importante comunidad de mudéjares convertidos ante de la conversión general de $1502^{67}$. Cuando el marqués de aquel señorío hizo valer que tenían privilegios y que nunca habían sido castigados por la Iglesia o la Inquisición, escaparon de la primera expulsión pero no de la segunda. A pesar de una carta audaz elevada al rey, en uno de los únicos alegatos en defensa de los moriscos hecho por un noble andaluz, el marqués de la Algaba y Ardales recordaba al monarca, cuando ya parte de sus vasallos habían sido embarcados y esperaban los vecinos del pueblo para serlo, que el segundo bando

\begin{abstract}
es caso confusísimo y ocasionado para grandes deservicios de nuestro Señor porque las pasiones y enemistades de algunos se extienden a delatar de algunos que han estado en posesión de cristianos viejos y tratádose como tales y emparentado con mucho bueno de estos reinos; cuyos parientes van sintiendo estas lástimas de manera que podría dar cuidado por el que a ellos les da ver llevar sus nietos y descendientes, que en tan buena opinión estaban y quitarles sus haciendas, fuera de la ocasión que se da a tantos perjuros como se van causando por remitirse estas causas a probanza; y Vuestra Majestad crea que si salen todos los que están en tan buena opinión, que ha de ser un gran número, y notable la falta que ha de hacer en sus reinos ${ }^{68}$.
\end{abstract}

Los 400 moriscos del marquesado y del pueblo del Algaba pidieron ser enviados a tierras de cristianos y fueron expulsados hacia Marsella como los otros moriscos que habían logrado sustraerse al primer bando de expulsión. En el mismo tiempo, los moriscos que se habían vuelto fueron azotados y echados a galeras.

\title{
El fin de la operación
}

En noviembre de 1612, el duque del Lerma escribía al conde de Salazar que la expulsión no llevaba trazas de ser completa y que debían resolverse las dificultades ${ }^{69}$. Tras terminar Marimón sus actuaciones, don Juan Lope de Zerón fue nombrado en 1612 para ocuparse de una misión circunscrita a expulsar los moriscos que se habían vuelto ya sin entrar sobre la espinosa cuestión de las exenciones obtenidas por los que se habían quedado. Se trataba de los últimos reductos de moriscos y tuvo enfrentamientos vivos con los corregimientos, pidiendo en julio de 1612 que les fueran concedidos

${ }^{66}$ A. G. S., E. 233, carta de D. A. de Marimón, del 5.11.1611

${ }^{67}$ Ver Gutiérrez Moya, C. «Los moriscos en La Algaba en el siglo XVI», en Actas del VIII Simposio Internacional de Mudejarismo, Teruel, 2002, pp. 685-695.

${ }^{68}$ A. G. S., E. 232, Carta del marqués del Algaba de Ardales a S. M., del 5.7.1611. Véase el apéndice.

${ }^{69}$ Bleda J., Coronica... 1058 
poderes más amplios ${ }^{70}$. Las fricciones con las justicias locales fueron sobradamente fuertes $^{71}$. Los procesos fueron encargados al licenciado Aguilera en Sevilla; en 1612, éste tenía detenidos a unos 30 moriscos y varios testimonios dejaban entender que seguían muchos moriscos en Sevilla ${ }^{72}: 200$ moriscos estaban detenidos en 1613 pero faltaban fondos para embarcarlos ${ }^{73}$. Señal de la desesperada obstinación de los moriscos y de los apoyos con los que podían valerse en Sevilla como en el resto de Andalucía, fueron intentando permanecer escondidos o bajo el amparo de los corregimientos.

Más tarde, a 16 de enero de 1613 se despachó orden general a las justicias avisándoles que habían de rematar la expulsión de los moriscos y, en 20 de abril de 1613, se dio nueva comisión al conde de Salazar para perfeccionar aquella obra y se quitó el conocimiento de las causas al Consejo Real y a todas la justicias ordinarias ${ }^{74}$. A principios de 1614, la expulsión fue dada por acabada oficialmente; como lo recordaba J. Bleda "el mayor trabajo fue resolver y averiguar los pleitos de los que en Castilla pretendían no ser comprendidos en los bandos". Todos los que ganaron sus procesos eran más de 700 familias según el conde de Salazar en 1613 sin contar las personas en Sevilla y Granada ${ }^{75}$. Cuántos quedaron o lograron volver, resulta imposible saberlo; Lapeyre los estima en 10 o 15000 personas para la península. En ciertos pueblos de Castilla, volvieron en número extremadamente elevado según T. Dadson $^{76}$.

\section{Conclusión}

La primera expulsión de Andalucía se había realizado en un plazo breve entre el momento en que don Juan de Mendoza recibía su nombramiento para "expeler" a los moriscos de Andalucía, de Murcia y de la villa de Hornachos, en noviembre de 1609, y el momento en que se finalizó el operativo y empezó el de Castilla en la primavera de 1610. El desplazamiento masivo de la población morisca distó mucho de ser eficiente, a pesar de la intransigencia manifestada a la hora de aplicarse los bandos y del número de desplazados. Las innovaciones constantemente aportadas, el tiempo que tardó el Consejo Real en resolver las dudas que surgían a la hora de interpretar los bandos como las resistencias que éstos pudieron generar en ciertos sectores redujeron el alcance de la medida. El choque de intereses y el juego político entre los cabildos locales y el poder central aminoró el alcance de la expulsión a pesar de la aparente aceptación de la medida real ${ }^{77}$. Las órdenes posteriores de completar y acabar dicha

\footnotetext{
${ }^{70}$ Lapeyre, H., Géographie..., p. 181.

${ }^{71}$ Ibiden.

${ }^{72}$ Moret, M., La société marchande de Séville, París, 1967, p. 100.

${ }^{73}$ A. G. S., E. 253, carta del duque de Lerma del 21.2.1613.

${ }^{74}$ Bleda J., Coronica... p. 1058

${ }^{75}$ Lapeyre, H., Géographie..., p. 209.

${ }^{76}$ Dadson, T. J., Los moriscos de Villarrubia de los Ojos: (siglos XV-XVIII) : historia de una minoría asimilada, expulsada y reintegrada, Madrid, 2007, pp. 613-638.

${ }^{77}$ Ver Chaves, Manuel F., Pérez García, Rafael, En los márgenes de... p. 363 y ss.
} 
operación daban cuenta del carácter apresurado del primer operativo y de las numerosas complicidades de la que habían podido valerse los moriscos a la hora de quedarse.

Es indudable que muchos volverían en los años posteriores, produciéndose un goteo incesante de moriscos que se retornaban hacia la península desde el exilio en Europa o las costas fronteras de África.

Pocas informaciones tenemos sobre aquellas vueltas a Sevilla aún si no por la actividad del Santo Oficio que pasó a procesar durante todo el reinado de Felipe III a aquellos que se habían venido desde las tierras musulmanas donde habían apostatado y renegado de su fe cristiana ${ }^{78}$. Planteaban un problema de fondo al tribunal, el de la actitud que guardar con ellos. A menudo forzados a renegar contra su voluntad, por hallarse en una situación a la que les había abocado la decisión regia, fueron tratados con una relativa benevolencia por los jueces inquisitoriales, sobre todo a partir del reinado de Felipe IV, cuando el monarca pidió a los corregidores que dejaran de aplicar las medidas dictadas contra los expulsados que volvían a sus tierras. El 19 de septiembre de 1628, el Consejo de la Suprema Inquisición instó a los inquisidores de Sevilla que no procedieran contra los moriscos expulsados "sino en caso que den escándalo ${ }^{79}$.

Es indudable que, a semejanza del morisco Ricote en El Quijote, muchos habían vuelto con falsas identidades a las tierras de sus antepasados. Entre 1610 y 1628 apenas se registran unos doce casos juzgados por el tribunal de Sevilla, una cifra relativamente baja; tanto más que la casi totalidad de estos apóstatas eran "espontáneos", es decir que se presentaron de su propia iniciativa ante el tribunal muchas veces para escapar de las galeras donde se hallaban condenados, el tiempo que durara el procedimiento inquisitorial. Aquello confirma que constituían sólo una proporción mínima de aquellos que habían vuelto.

\footnotetext{
${ }^{78}$ A.H.N. Inquisición, leg. 2965 exp. s/n, carta del tribunal al Consejo del 26.9.1628.

${ }^{79}$ Ibiden. El inquisidor consideró que esta reserva había de ser entendida de forma «que si algunos de los dichos moriscos vueltos a España quisiesen vivir entre cristianos en su seta con nota y escándalo». Pero reconoce a la vez que en Sevilla hay muchos apóstatas y «los permite... y muchos [de éstos] públicamente se toleran en las galeras». De hecho, la totalidad de aquéllos quienes, expulsados, apostataron, no eran perseguidos por la Inquisición; todos se presentaron de su propia voluntad ante el tribunal: Boeglin, M., L'Inquisition espagnole au lendemain du concile de Trente, Montpellier, 2001, p. 274-275. Ver también Martinez, François, La permanence morisque en Espagne après 1609. Discours et réalités, Tesis de doctorado, publicada en Lille, 1999.
} 


\title{
Apéndice. Carta del marqués de La Algaba a Su Majestad. 5 de julio de $1611^{80}$.
}

\author{
A.G.S. Fondo Estado 232. \\ Señor,
}

Aunque es de creer que negocio tan grande, como el de la expulsión de los moriscos, se habrá mirado por las personas, a quien Vuestra Majestad lo mandó cometer antes de publicar los primeros y últimos bandos con la consideración a que obliga la gravedad de él, humildemente suplico a Vuestra Majestad se mire muy atentamente los inconvenientes que podrían resultar contra el servicio de nuestro Señor y el de Vuestra Majestad en el expeler a todos los que descienden de moriscos aunque sean de los antiguos como por este último bando lo manda Vuestra Majestad, que toca a mucho bueno de sus reinos y si la expulsión antigua que los Señores Reyes Católicos de gloriosa memoria mandaron hacer de los judíos de estos reinos se extendiera a los antiguos descendientes de ellos considere Vuestra Majestad a lo que aquello llegaría. En el primero bando de estos últimos mandaba Vuestra Majestad que también se entendiese con los antiguos, que como tales se hubiesen tratado y vivido en barrios separados usando de algunos ritos o ceremonias como lo demás. Con esto, Señor, había una clara distinción. Pero ahora que Vuestra Majestad manda que todos salgan sin ninguna reserva es caso confusísimo y ocasionado para grandes deservicios de Nuestro Señor porque las pasiones y enemistades de algunos se extienden a delatar de algunos que han estado en posesión de cristianos viejos y tratádose como tales y emparentado con mucho bueno de estos reinos; cuyos parientes van sintiendo estas lástimas de manera que podría dar cuidado por el que a ellos les da ver llevar sus nietos y descendientes, que en tan buena opinión estaban y quitarles sus haciendas, fuera de la ocasión que se da a tantos perjuros como se van causando por remitirse estas causas a probanza; y Vuestra Majestad crea que si salen todos los que están en tan buena opinión, que ha de ser un gran número, y notable la falta que ha de hacer en sus reinos donde muchos de éstos han tenido en la paz y en la guerra honrosos cargos y el tocar en ella cosa que tanto pesa a los que a éstos tocan (sic) es muy considerable. Que esto se ejecute en los listados, empadronados o que han pagado farda $\mathrm{u}$ otros derechos como tales o en los que han vivido en algunas diferencias a su modo parece que tiene menos inconveniente ya que Vuestra Majestad sea servido de ello. Pero en lo demás es caso grave. Suplico a Vuestra Majestad lo considere y reciba mi voluntad que como estoy a pie de obra voy tocando lo que me ha parecido advertir a Vuestra Majestad forzoso por cumplir con la fidelidad de vida, sin que mueva ningún otro respeto humano porque los moriscos que había en mis tierras han salido ya y los de El Algaba están listados y en orden para hacerlo cuando la persona a quien Vuestra Majestad lo ha cometido les ordenare si no les ha de valer los privilegios cédulas reales y ejecutorias que ante Vuestra Majestad han presentado cuya causa aun pende ante Vuestra Majestad Guarde Dios a Vuestra Majestad como la cristiandad ha menester y los vasallos de Vuestra Majestad deseamos. En El Algaba, cinco de julio mil seiscientos y once años.

El marqués del Algaba y de Ardales

${ }^{80}$ A. G. S. Fondo Estado 232. 